\title{
System Dynamics Modeling for Sustainable Water
} \section{Management of a Coastal Area in Shandong Province,} China

\author{
Qin Huanhuan ${ }^{1}$, Zhang Baoxiang ${ }^{2}$ and Meng Fanhai ${ }^{3}$ \\ 1. Institute of Water Sciences and College of Engineering, Peking University, Beijing 100871, China \\ 2. Water Resources Research Institute of Shandong Province, Jinan 250013, Shandong, China \\ 3. Water Bureau of Longkou City, Longkou 265701, Shandong, China
}

\begin{abstract}
Water is one of the basic materials in human existence and the development of society and economy. Its sustainable management has always been an eternal subject for the management of human society and also a complex systemic problem. How to take advantages of water has been a big event in such an agricultural country like China. As economically developed areas, coastal areas are facing water shortage problems due to the rapid economic and social development and inappropriate and unsustainable water management measures. To fully understand and study such problems faced by the coastal areas needs a systematic and integrated framework to consider the various social-economic, natural and engineering factors that affect the sustainable development of water in those areas. The SD (system dynamics) methodology, which is an approach that has been successfully used in solving complex systematic problems in general, and in solving water management problems in particular for more than 50 years, was applied to a typical coastal area, Longkou City in Shandong Province of China, to study and analyze the future sustainable water management of this city. Then the quantitative modeling and analysis of the water development were carried out through scenario analysis. Four different scenarios (business as usual, economic development, water resources protection, and comprehensive) were designed by changing the values of decision-making variables. The total water demand in 2030 of these four scenarios are 0.455 billion $\mathrm{m}^{3}, 0.793$ billion $\mathrm{m}^{3}, 0.412$ billion $\mathrm{m}^{3}$ and 0.487 billion $\mathrm{m}^{3}$, respectively; the corresponding water deficit of these scenarios are 0.292 billion $\mathrm{m}^{3}, 0.634$ billion $\mathrm{m}^{3}, 0.254$ billion $\mathrm{m}^{3}$ and 0.329 billion $\mathrm{m}^{3}$, respectively. The comparison results indicated that the comprehensive scenario is the optimal one among these designed scenarios. To totally solve the water shortage problem with the economy developed in Longkou City needs to take more effective measures to reduce water consumption and improve water conservation technologies.
\end{abstract}

Key words: Sustainable water management, coastal areas, system dynamics, scenario analysis.

\section{Background and Objectives}

Water is one of the basic materials in human existence and the development of society and economy. Its sustainable management has always been an eternal subject for the management of human society and also a complex systemic problem. How to take advantages of water has been a big event in such an agricultural country like China. Simultaneously, the management and sustainable exploitation of water

Corresponding author: Qin Huanhuan, Ph.D., lecturer, research fields: hydrological modelling and water resources management. resources is crucial to a region's economic planning and development. As a result of the rapid economic development in China in general and in coastal areas in particular, the demand for water has been always increasing in the coastal areas. The root causes of the water deficit problems in China can be summarized as wide spread drought, the spread of pollutants, rapid economic expansion, and regional differences of water resources distribution. However, these problems have tight relationship with the inappropriate exploitation and management of water resources. Therefore, sustainable management of water is one of the key attributes that impact environment at every spatial 


\section{Area in Shandong Province, China}

scale from local watershed to global water cycle.

As economically developed areas, coastal areas are facing water shortage problems due to the rapid economic and social development and inappropriate and unsustainable water management measures. Longkou City, located in the northern Jiaodong peninsula with the longitude of $120^{\circ} 12^{\prime} 14^{\prime \prime}$ to $120^{\circ} 44^{\prime} 46^{\prime \prime}$ and latitude of $37^{\circ} 27^{\prime} 30^{\prime \prime}$ to $37^{\circ} 47^{\prime} 24^{\prime \prime}$, and a total area of 893.32 $\mathrm{km}^{2}$ (Fig. 1), is a typical economic developed coastal area in Shandong Province of China facing serve water shortage problem. By 2010, the total population of Longkou was 0.64 million and the regional GDP was 68 billion RMB (China's currency), ranking first among all counties in Shandong. Longkou has a type of warm temperate semi humid continental monsoon climate, with multi-year average precipitation of $586.3 \mathrm{~mm}$ and

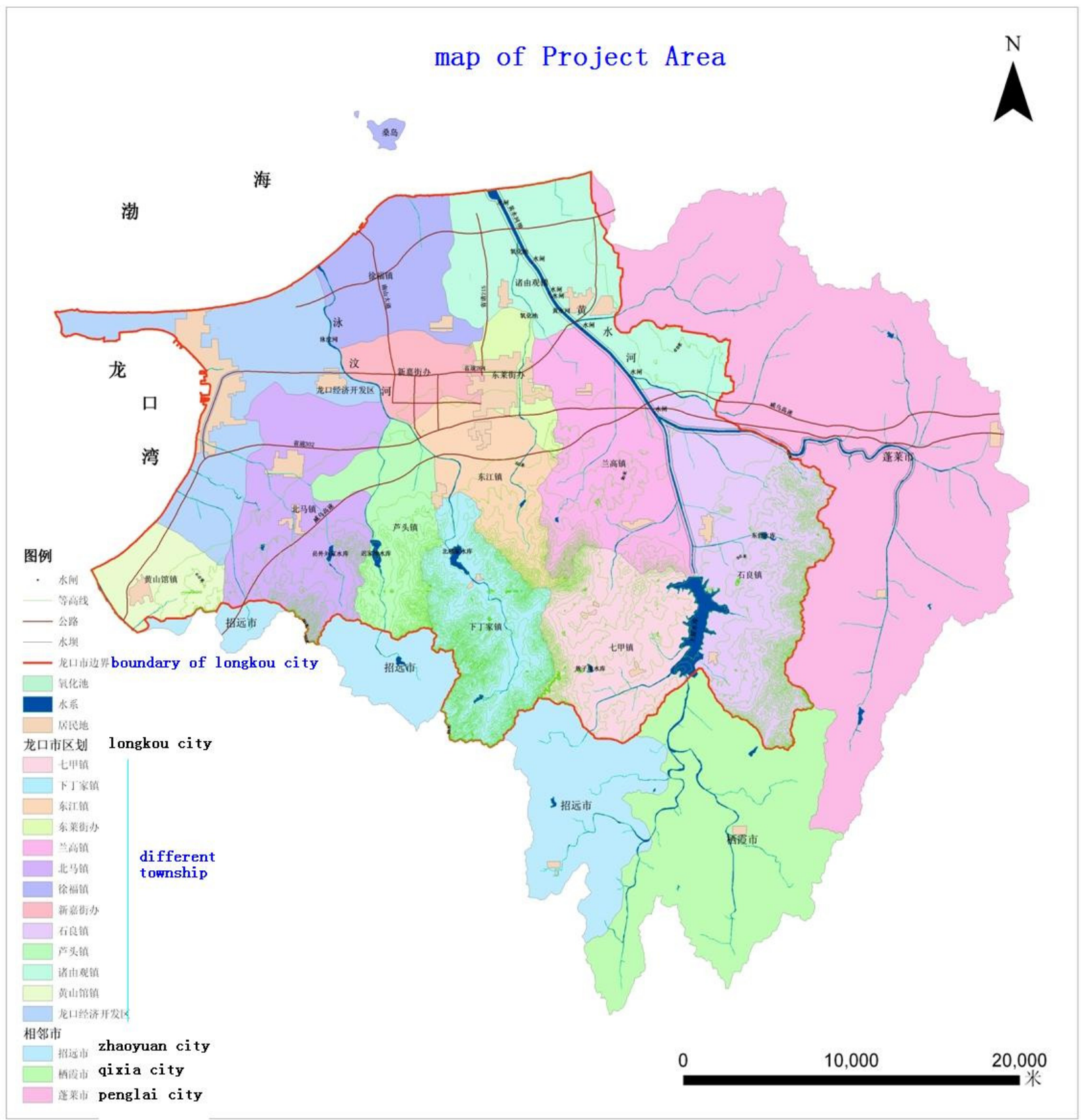

Fig. 1 Location of Longkou City. 


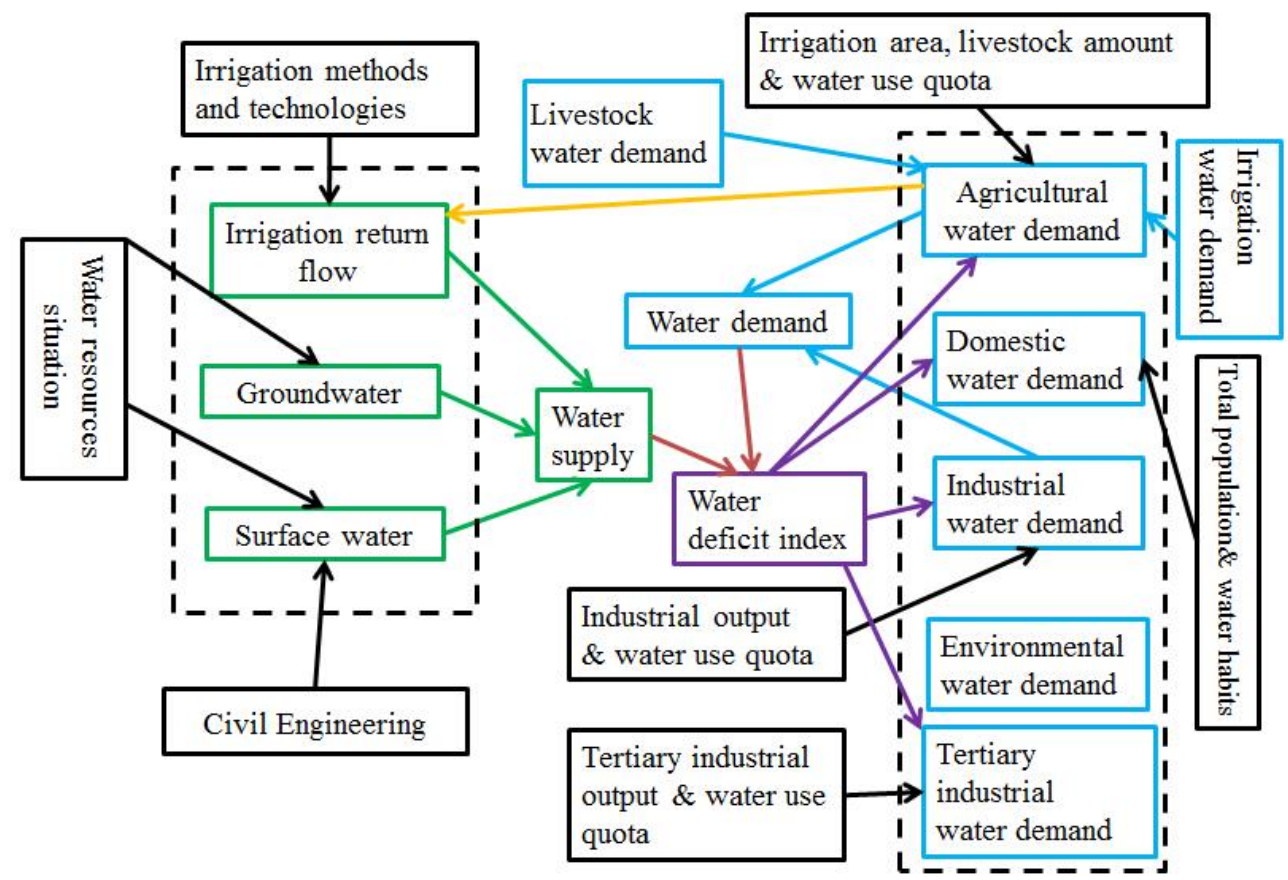

Fig. 2 Conceptual water balance diagram of Longkou water system.

about $72.9 \%$ of the precipitation in June to September. The inter-annual precipitation variation is very large, with a maximum precipitation of $1,046.2 \mathrm{~mm}$ in 1964 and a minimum precipitation of $329.4 \mathrm{~mm}$ in 1989 . The water resources of Longkou have the characteristics of limited water resources, uneven regional distribution, large inter-annual variability and consecutive wet or dry year. The problems existing in the current water development and utilization mainly include: water deficit, serious waste of water, deterioration of water ecological environment due to the excessive exploitation of water, disrepair and ageing of small water conservancy projects, and less enough attention paid to water management.

In this study we have developed a model based on the SD methodology, which considers socio-economic, technologic and hydrological factors affecting the water utilization processes, to simulate the future water demands under different scenarios for Longkou City, in order to fully understand the complex water demand and supply system, compare the results of different development scenarios and provide reasonable suggestions on the sustainable water management to the policy makers based on the modeling results of this study.

\section{Methods and Model Structure}

SD (system dynamics) was first founded by Forrester, J. W., a professor at the MIT (Massachusetts Institute of Technology), in 1956 [1]. The understanding of close relationships of amongst components is represented by a mathematical modeling framework equipped with feedback control theory. SD is advantageous in dealing with a high degree of non-linear, high-level, and multi-variable problems [2]. SD has been shown to be useful by many studies for its capability to deal with water scarcity problems with both interactive and non-linear relationships and complex behaviors [3-5]. The applications of SD in water management and future water demands prediction are widespread (e.g., see Refs. [6-14]).

Fig. 2 shows the conceptual water balance diagram of Longkou water system, while Fig. 3 shows the flow chart of the SD model for water management in Longkou City. The balance of water supply and demand 


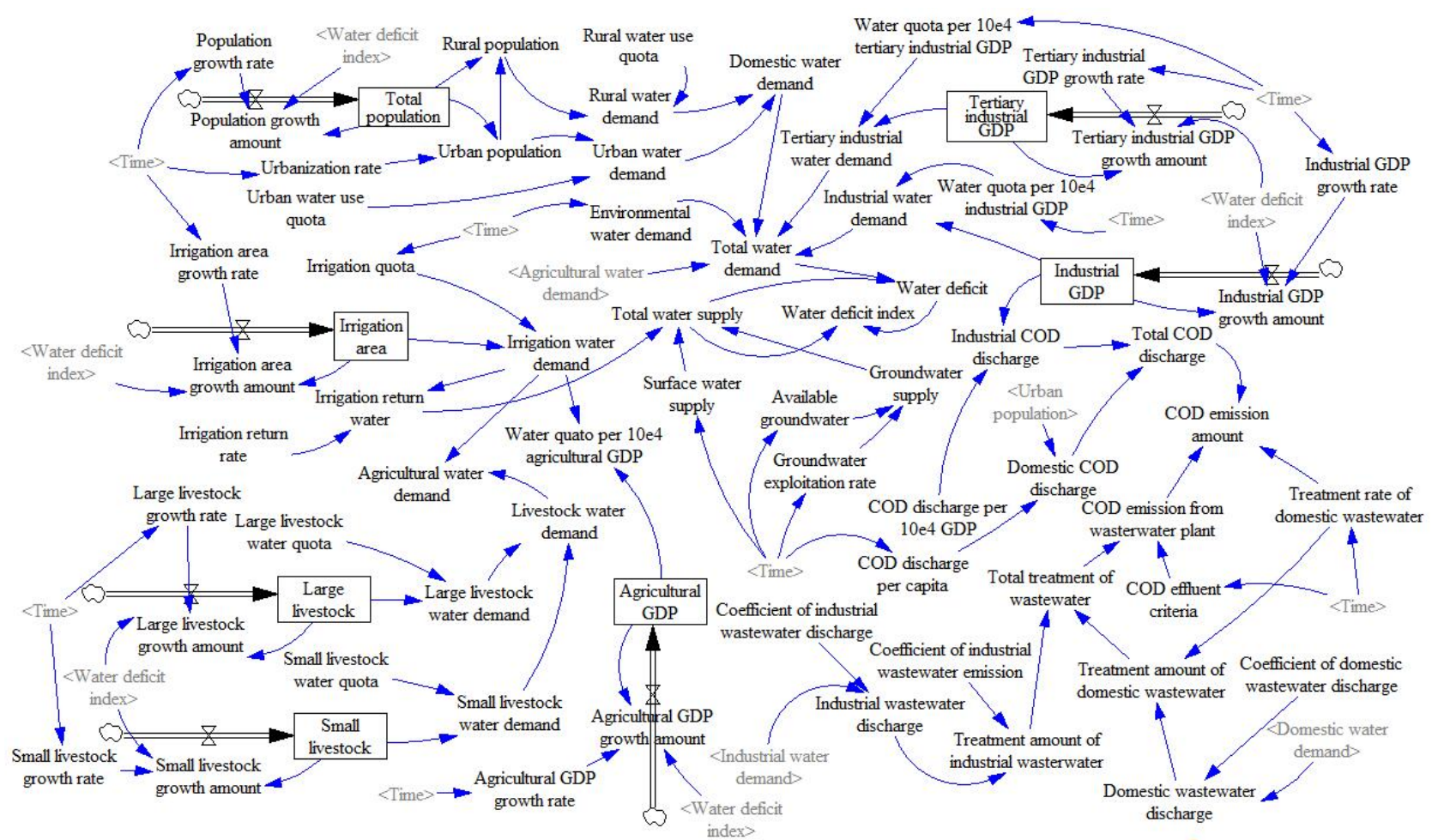

Fig. 3 Flow chart of the SD model for water management in Longkou City.

defines the water deficit situation of Longkou water system. The water supply sector includes groundwater, surface water and irrigation return water, while the water demand sector includes domestic, industrial, tertiary industrial, agricultural, and environmental water demands. Therefore, the water system was divided into 5 sub-systems, including population, agricultural, industrial and tertiary industrial, water environmental, and water resources sub-systems. Each sub-system was interrelated and mutually influenced by other sub-systems. The logical feedback relationships and quantitative equations were achieved through the building of the flow chart (Fig. 3).

The simulation of an SD model is carried out according to certain steps along the time axis. The variables that represent the states of the system will be updated at the end of each time step, while the initial values of the variables will be used at the first step of the simulation. The variables in SD are mainly categorized into five types [1-2]: flow variables, flow rate variables, constants, auxiliary variables and table functions. These are required relational inputs into the
VENSIM software. The flow variables express the cumulative quantities, the flow rate variables express the rate of change to cumulative quantities, the auxiliary variables are the intermediate ones between the flow variables and the flow rate variables and the constants do not change over time in an interval time. The table functions are used to express the non-linear relationship between some variables in the model. There are more than 60 variables and parameters. The causal and logical relationships amongst the variables, flow rates and table functions are abstracted into mathematical relations (i.e. state and auxiliary equations), to conduct quantitative analysis. More details of how equations are constructed can be found in Ref. [1].

\section{Model Setups and Simulation Results}

The simulation region is Longkou City, including 13 towns in this region. The simulation period is 2000-2030 with the time step of one year. The modeling period spans two stages: the first stage is from 2000 to 2008 and is known as the model calibration stage; the 
Table 1 Historical test of total population.

\begin{tabular}{llll}
\hline Year & Historical Value $\left(10^{4}\right.$ capita $)$ & Simulation value $\left(10^{4}\right.$ capita $)$ & Related error $(\%)$ \\
\hline 2000 & 62.31 & 62.31 & 0.00 \\
2001 & 62.46 & 62.61 & 0.24 \\
2002 & 62.62 & 62.91 & 0.46 \\
2003 & 62.58 & 63.20 & 0.99 \\
2004 & 62.82 & 63.48 & 1.05 \\
2005 & 63.08 & 63.75 & 1.06 \\
2006 & 63.25 & 64.02 & 1.22 \\
2007 & 63.44 & 64.27 & 1.31 \\
2008 & 63.38 & 64.52 & 1.80 \\
\hline
\end{tabular}

second stage is from 2009 to 2030 and is known as the model prediction stage. The model calibration stage is focused on obtaining reasonable parameter values by matching model output to historical data, while the model prediction stage focuses on modeling the future water management situations through scenario analysis method using the calibrated parameter values.

\subsection{Calibrations to Historical Data}

Calibration of the model must be carried out before the analysis. Simulation results are compared with the actual historical data to verify the extent of their agreement, in order to assess the reliability of model parameters and accuracy of the simulation model. Table 1 is the comparison of total population between simulated and historical data for the period 2000-2008. Overall, the simulated results are similar to the historical data, with a maximum related error of $1.8 \%$. The calibrated model can be used in the prediction period to conduct a scenario analysis for the water system of Longkou.

\subsection{Scenarios Design}

After the model has a set of rate quantities that match well with historical rates, the scenario analysis of Longkou's water system is conducted. Specifically, the decision variables (the urbanization level, industrial/tertiary industrial GDP growth rate, industrial/tertiary industrial water used per $10^{4} \mathrm{RMB}$, irrigation quota, treatment rate of domestic wastewater, and domestic COD discharge per capita) are selected to design four different policy scenarios. These are further described below.

(1) Scenario 0: this scenario is also called business-as-usual scenario by assuming that the development policies and system structure do not have a large adjustment in the forecasting period. The constant parameters are the same as in the model calibration stage while the table-function parameters are hypothesized with a moderate trend. According to the actual situation of Longkou and the author's experience, the industrial GDP growth rate is set to be $16 \%, 12 \%$, and $8 \%$ in 2010, 2020 and 2030, respectively; while the tertiary industrial GDP growth rate is $11 \%, 10 \%$ and $8 \%$ in 2010,2020 and 2030, respectively. The urbanization level will be $45 \%, 52 \%$ and 55\% in 2010, 2020 and 2030, respectively.

(2) Scenario 1: this scenario is known as economic development scenario by stressing the importance of economic development. Economic development remains the top priority of Longkou in the present and future for a long time. Therefore, increase the growth rate of industrial GDP to $18 \%, 16 \%$ and $12 \%$ in 2010 , 2020 and 2030, respectively; and increase the growth rate of the tertiary industrial GDP to $13 \%, 12 \%$ and $11 \%$ in 2010, 2020 and 2030, respectively; while the urbanization level will be increased to $62 \%$ in 2030 . Other parameters of this scenario keep the same as scenario 0 .

(3) Scenario 2: this scenario is called resources conservation scenario by protecting the water resources of Longkou. The water quota per $10^{4} \mathrm{RMB}$ of industrial GDP in 2010, 2020 and 2030 will be 18, 10 and $8 \mathrm{~m}^{3} / 10^{4} \mathrm{RMB}$, respectively; while the water 
quota per $10^{4} \mathrm{RMB}$ of tertiary industrial GDP in 2010, 2020 and 2030 will be $2,1.5$ and $1 \mathrm{~m}^{3} / 10^{4} \mathrm{RMB}$, respectively; the domestic COD discharge per capita in 2010,2020 and 2030 will be $8.8 \times 10^{-3}, 8.2 \times 10^{-3}$ and $7.8 \times 10^{-3}$ ton/capita, respectively.

(4) Scenario 3: this scenario is known as a sustainable development scenario by emphasizing economic development and protection of water resources at the same time. Domestic waste water treatment rate in 2010, 2020 and 2030 will be 90\%, 94\% and 97\%, domestic COD generated amount per capita in 2030 is reduced to $7.8 \times 10^{-3}$ ton/capita, the amount of COD generated per $10^{4} \mathrm{RMB}$ of industrial
GDP in 2030 is reduced to $4.5 \times 10^{-4}$ ton $/ 10^{4} \mathrm{RMB}$. Urbanization rate in 2030 will reach $57 \%$, industrial GDP growth rate in 2020 and 2030 will be $13 \%$ and $11 \%$, tertiary industry GDP growth rate in 2030 will fall to $10 \%$, crop irrigation quota in 2030 will drop to $1,425 \mathrm{~m}^{3} / \mathrm{ha}$.

\subsection{Results}

The comparison results can be analyzed from three aspects: the total water demand, the water deficit and COD emission amounts. Table 2 is the simulation results under the four scenarios. Figs. 4-6 show the plot figures of these three variables over time. From

Table 2 Simulation results under the four scenarios.

\begin{tabular}{|c|c|c|c|c|c|}
\hline \multirow{2}{*}{ Variable } & \multirow{2}{*}{ Year } & \multicolumn{4}{|l|}{ Scenarios } \\
\hline & & Scenario 0 & Scenario 1 & Scenario 2 & Scenario 3 \\
\hline \multirow{5}{*}{$\begin{array}{l}\text { Total population } \\
\left(10^{4} \text { capita }\right)\end{array}$} & 2010 & 65.00 & 65.00 & 65.00 & 65.00 \\
\hline & 2015 & 66.11 & 66.10 & 66.11 & 66.11 \\
\hline & 2020 & 67.15 & 67.14 & 67.15 & 67.15 \\
\hline & 2025 & 68.11 & 68.10 & 68.12 & 68.12 \\
\hline & 2030 & 69.00 & 68.97 & 69.01 & 69.00 \\
\hline \multirow{5}{*}{$\begin{array}{l}\text { Industrial } \\
\text { GDP } \\
\left(10^{10} \mathrm{RMB}\right)\end{array}$} & 2010 & 4.192 & 4.520 & 4.193 & 4.193 \\
\hline & 2015 & 8.489 & 10.13 & 8.495 & 8.571 \\
\hline & 2020 & 15.69 & 21.62 & 15.72 & 16.35 \\
\hline & 2025 & 26.46 & 43.02 & 26.54 & 29.34 \\
\hline & 2030 & 40.58 & 77.28 & 40.77 & 49.99 \\
\hline \multirow{5}{*}{$\begin{array}{l}\text { Tertiary } \\
\text { industrial GDP } \\
\left(10^{10} \mathrm{RMB}\right)\end{array}$} & 2010 & 1.332 & 1.442 & 1.332 & 1.387 \\
\hline & 2015 & 2.221 & 2.627 & 2.222 & 2.420 \\
\hline & 2020 & 3.612 & 4.657 & 3.616 & 4.117 \\
\hline & 2025 & 5.670 & 8.008 & 5.684 & 6.823 \\
\hline & 2030 & 8.466 & 13.270 & 8.501 & 10.980 \\
\hline \multirow{5}{*}{$\begin{array}{l}\text { Total } \\
\text { water demand } \\
\left(10^{4} \mathrm{~m}^{3}\right)\end{array}$} & 2010 & 16,126 & 16,778 & 15,642 & 15,466 \\
\hline & 2015 & 20,867 & 23,424 & 19,951 & 19,907 \\
\hline & 2020 & 25,503 & 32,204 & 23,890 & 24,413 \\
\hline & 2025 & 35,021 & 51,947 & 32,251 & 34,733 \\
\hline & 2030 & 45,529 & 79,256 & 41,212 & 48,651 \\
\hline \multirow{5}{*}{$\begin{array}{l}\text { Water } \\
\text { deficit } \\
\left(10^{4} \mathrm{~m}^{3}\right)\end{array}$} & 2010 & 500.61 & 1,152 & 16.81 & -128.4 \\
\hline & 2015 & 5,123 & 7,679 & 4,206 & 4,192 \\
\hline & 2020 & 9,636 & 16,336 & 8,022 & 8,576 \\
\hline & 2025 & 19,180 & 36,106 & 16,410 & 18,921 \\
\hline & 2030 & 29,172 & 63,439 & 25,395 & 32,864 \\
\hline \multirow{5}{*}{$\begin{array}{l}\text { COD } \\
\text { emission amount } \\
\text { (ton) }\end{array}$} & 2010 & 3,644 & 3,898 & 3,316 & 3,322 \\
\hline & 2015 & 5,562 & 6,581 & 5,004 & 5,051 \\
\hline & 2020 & 7,400 & 10,098 & 6,481 & 6,736 \\
\hline & 2025 & 11,025 & 17,782 & 9,580 & 10,576 \\
\hline & 2030 & 14,880 & 28,183 & 12,786 & 15,654 \\
\hline
\end{tabular}




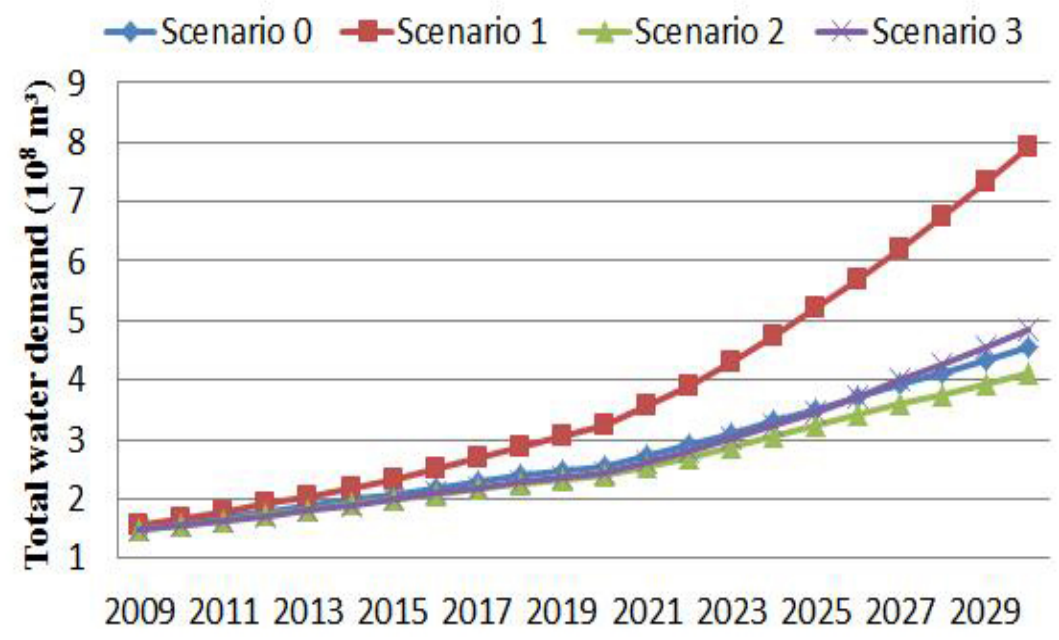

Fig. 4 Total water demand of the four scenarios for the prediction period.

Fig. 4 we can see that the total water demand of all the four scenarios are 0.455 billion $\mathrm{m}^{3}, 0.793$ billion $\mathrm{m}^{3}$, 0.412 billion $\mathrm{m}^{3}$ and 0.487 billion $\mathrm{m}^{3}$ in 2030, respectively. The total water demand increases as the economy develops whatever scenario is adopted by Longkou in future time. The total water demand under scenario 2 is the least among these four scenarios. The corresponding water deficits of the four scenarios are 0.292 billion $\mathrm{m}^{3}, 0.634$ billion $\mathrm{m}^{3}, 0.254$ billion $\mathrm{m}^{3}$ and 0.329 billion $\mathrm{m}^{3}$ in 2030, respectively (Fig. 5). There are still water deficit problems in these four scenarios by the end of the simulation period. As scenario 3 has considered both economic development and water resources protection, the water deficit of this scenario is more than that of scenario 0 in the last five years of the simulation period (2026-2030) while it is less than that of scenario 0 in other years. Meanwhile, although the water deficit in scenario 2 is the least, the economic development of this scenario is limited a lot. It is not a suitable scenario under the background of the emphasis on the development of economy.

The COD emission amounts of these four scenarios are different, as they have different emphasis (Fig. 6). The COD emission amount in scenario 1 is the most among all these scenarios as the economic development is over emphasized in scenario 1. Both the economic development and environmental protection are emphasized in scenario 3, so the COD emission amount in this scenario is the least. The COD emission amount can be treated as an index of whether the environment is good or bad. Therefore, the scenario 3 is a good way to coordinate the relationship between economic development and water resources and environmental protection, as it not only pays attention to the development of economy, but also pays attention to the environmental protection.

The sustainable development scenario (scenario 3) is the optimal one among all these four scenarios from the aspects of total water demand, water deficit and COD emission amount. This scenario is the one Longkou will take in future time. Over emphasis of economic development (scenario 1), over emphasis of water resources protection (scenario 2) and keeping the trend of present time (scenario 0) will result an unbalance between the economic development and water resource use. The society can be sustainably developed only with the balance of economic development and water resource protection. In scenario 3, Longkou has a moderate economic development rate and a moderate pressure and demand for water resources and environment, and therefore the society can be sustainably developed with the economy and water resources. 


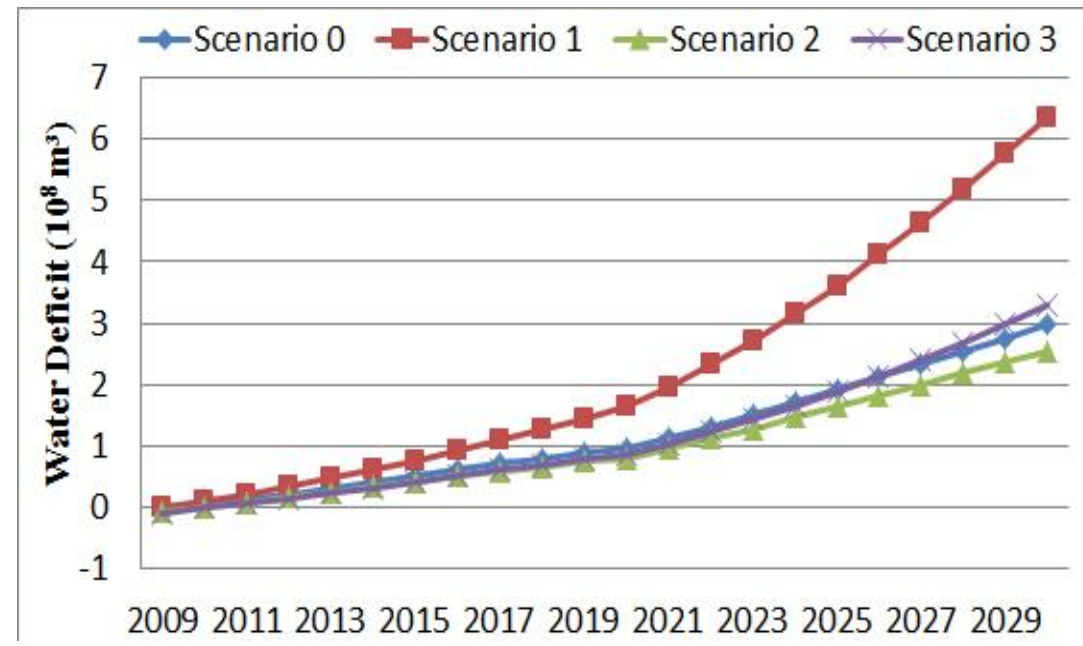

Fig. 5 Water deficit of the four scenarios for the prediction period.

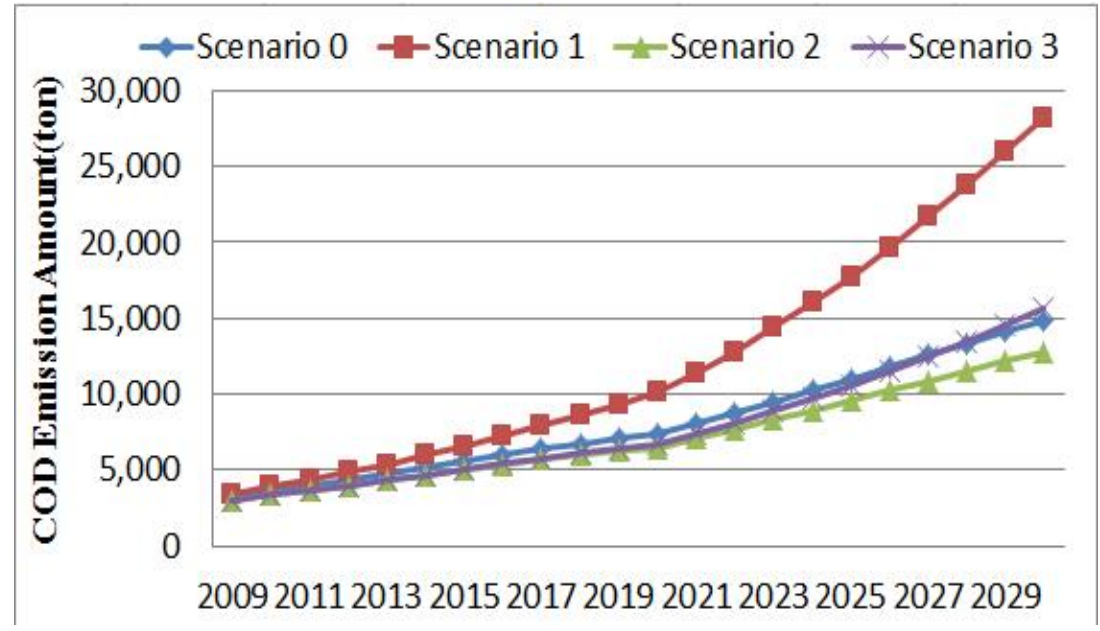

Fig. 6 COD emission amounts of the four scenarios for the prediction period.

\section{Conclusions}

The water issues will become more prominent in the $21^{\text {st }}$ century, while the generation and development of sustainable development strategy provides a new train of thought to solve water crisis. This study has discussed the water management based on the theory of system dynamics, in order to achieve the goal of sustainable utilization of water resources. Longkou city in Shandong Province of China has been selected as the study region and a system dynamics model of water resources management in Longkou has been established. The future predictions of water utilization for Longkou have been carried out based on four development scenarios. The total water demand in
2030 of these four scenarios are 0.455 billion $\mathrm{m}^{3}$, 0.793 billion $\mathrm{m}^{3}, 0.412$ billion $\mathrm{m}^{3}$ and 0.487 billion $\mathrm{m}^{3}$, respectively; the corresponding water deficit of these scenarios are 0.292 billion $\mathrm{m}^{3}, 0.634$ billion $\mathrm{m}^{3}, 0.254$ billion $\mathrm{m}^{3}$ and 0.329 billion $\mathrm{m}^{3}$, respectively. The comparison results indicated that the comprehensive scenario is the optimal one among these designed scenarios. To totally solve the water shortage problem with the economy developed in Longkou City needs to take more effective measures to reduce water consumption and improve water conservation technologies. The results show that the system dynamics method is advantageous in dealing with a high degree of non-linear, high-level, and multi-variable problems. The method of this study can 
be generalized to other coastal areas in many aspects, including the model construction, the equation establishment, data acquisition, scenario design and results analysis and comparison. However, the best model should be established by analyzing the specific problems in specific area and according to the characteristics of the study area itself.

\section{Acknowledgment}

The project was supported by research fund of the Key Laboratory of Water Resources and Environment of Shandong Province, China.

\section{References}

[1] Wang, Z. J. 1988. Introduction to System Dynamics. Shanghai: Shanghai Scientific and Technical Literature Press. (in Chinese)

[2] Wang, Q. F. 1995. Advanced System Dynamics. Beijing: Tsinghua University Press. (in Chinese)

[3] Winz, I., Brierley, G., and Trowsdale, S. 2009. "The Use of System Dynamics Simulation in Water Resources Management." Water Resour. Manage. 23 (7): 1301-23.

[4] Mirchi, A., Madani, K., Watkins, Jr. D., and Ahmad, S. 2012. "Synthesis of System Dynamics Tools for Holistic Conceptualization of Water Resources Problems." Water Resour. Manage. 26: 2421-42.

[5] Dai, S., Li, L., Xu, H., Pan, X., and Li, X. 2013. "A System Dynamics Approach for Water Resources Policy Analysis in Arid Land: A Model for Manas River Basin.” J. Arid Land 5 (1): 118-31.

[6] Camara, A., Viegas, M., and Amaro, A. 1986.
"Interfacing System Dynamics and Multi Objective Programming for Regional Water Resources Planning." Ann Reg. Sci. 20 (3): 104-13.

[7] Guo, H., Liu, L., Huang, G., Fuller, G., Zou, R., and Yin, Y. 2001. "A System Dynamics Approach for regional Environmental Planning and Management: A Study for the Lake Erhai Basin.” J. Environ. Manag. 61 (1): 93-111. doi: 10.1006/ jema.2000.0400.

[8] Xu, Z., Takeuchi, K., Ishidaira, H., and Zhang, X. 2002. "Sustainability Analysis for Yellow River Water Resources Using the System Dynamics Approach." Water Resour. Manage. 16 (3): 239-61. doi: 10.1023/A: 1020206826669.

[9] Sehlke, G., and Jacobson, J. 2005. "System Dynamics Modeling of Trans-Boundary Systems: The Bear River Basin Model." Ground Water 43 (5): 722-30. doi: 10.1111/j.1745-6584.2005.00065.x.

[10] Qin, H. H., Sun, A. C., Liu, J., and Zheng, C. M. 2012. "System Dynamics Analysis of Water Supply and Demand in the North China Plain." Water Policy 14: 214-31.

[11] Simonovic, S. P. 2002a. "Global Water Dynamics: Issues for the 21st Century." Water Sci. Technol. 45 (8): 53-64.

[12] Simonovic, S. P. 2002b. "World Water Dynamics: Global Modeling of Water Resources." J. Environ. Manag. 66: 249-67. doi:10.1006/jema.2002.0585.

[13] Simonovic, S. P., and Fahmy, H. 1999. "A New Modeling Approach for Water Resources Policy Analysis." Water Resour. Res. 35 (1): 295-61.

[14] Simonovic, S. P., and Rajasekaram, V. 2004. "Integrated Analyses of Canada's Water Resources: A System Dynamics Approach." Can. Water Resour. J. 29 (4): 223-50. 